\section{Commentary: Another way to band pulmonary arteries: Anatomic, hemodynamic, and scientific considerations}

\author{
David Kalfa, MD, PhD
}

In this issue of the JTCVS Techniques, Salve and colleagues ${ }^{1}$ describe a technique of a modified pulmonary artery banding (PAB) that consists of interposing an expanded polytetrafluoroethylene tube between the sinotubular junction of the neopulmonary root and the pulmonary artery (PA) confluence for children with transposition physiology. This technique can represent a new tool to our armamentarium with some advantages. It eliminates the risk of band migration and may also reduce the risk of neopulmonary root distortion, as it avoids infolding of the pulmonary arterial wall that can occur with standard external PAB. This patient series is obviously too small to demonstrate such a potential advantage. It is interesting though to note that 6 of 13 of these patients did require a branch PA plasty as an unplanned reintervention. We could wonder what the impact of the modified PAB was on the branch PAs in the setting of a Lecompte maneuver.

This technique may also have some disadvantages compared with a standard PAB. First, interposing a graft is a "definitive" way to band a PA; a standard PAB is a much more versatile technique in the sense that it can be subsequently loosened or tightened off bypass (by repositioning the sutures or the clips) depending on the patient physiology and hemodynamics. Second, given the

\footnotetext{
From the Section of Pediatric and Congenital Cardiac Surgery, Division of Cardiac, Thoracic and Vascular Surgery, New-York Presbyterian-Morgan Stanley Children's Hospital, Columbia University Medical Center, New York, NY.

Disclosures: The author reported no conflicts of interest.

The Journal policy requires editors and reviewers to disclose conflicts of interest and to decline handling or reviewing manuscripts for which they may have a conflict of interest. The editors and reviewers of this article have no conflicts of interest.

Received for publication July 22, 2021; revisions received July 22, 2021; accepted for publication July 26, 2021; available ahead of print July 30, 2021.

Address for reprints: David Kalfa, MD, PhD, Pediatric Cardiac Surgery, New-York Presbyterian-Morgan Stanley Children's Hospital, Columbia University Medical Center, New York, NY 10032 (E-mail: dk2757@cumc.columbia.edu).

JTCVS Techniques 2021;9:126-7

2666-2507

Copyright (C) 2021 The Author(s). Published by Elsevier Inc. on behalf of The American Association for Thoracic Surgery. This is an open access article under the CC BY-NC-ND license (http://creativecommons.org/licenses/by-nc-nd/4.0/). https://doi.org/10.1016/j.xjtc.2021.07.016
}

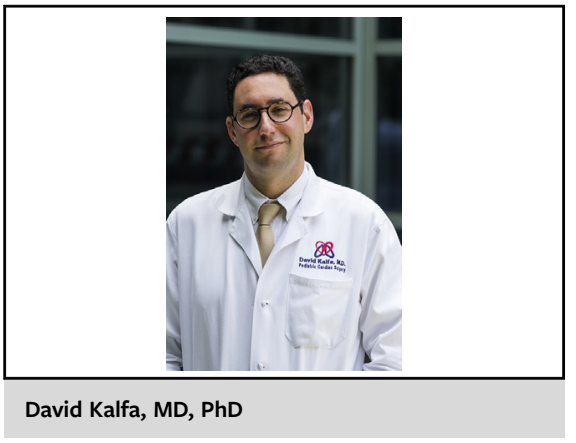

CENTRAL MESSAGE

The interposition of a synthetic

tube into the PA can be a

different way to band a patient

with pulmonary overcirculation.

Optimal diameter and length still

need to be determined.

significant size discrepancy between the tube and the proximal and distal native PA tissue, this technique requires a significant amount of additional work (and bypass/crossclamp times) to suture fenestrated patches on the PAs. Third, this PA band technique requires a complex reconstruction of the PAs at the time of the band takedown.

The length of this modified PA band is probably the most interesting aspect of this technique. The authors state that the length of the interposition graft was determined by the distance required to bridge the gap between the root and the confluence allowing a tension-free anastomosis. This anatomy-driven strategy does not take into account the resistance that the length of the PAB opposes to the blood flow. Indexing graft length to patient weight at the time of surgery revealed a median ratio of $1 \mathrm{~mm} / \mathrm{kg}$ for biventricular repair and $4 \mathrm{~mm} / \mathrm{kg}$ for univentricular repair. This finding is a retrospective finding from the authors and not a prospective and deliberated strategy, thus making the choice of the length quite uncertain. The use of finiteelement computational modeling can help the surgeon in an immense way in term of preoperative planning to determine not only the optimal diameter but also the optimal length of the expanded polytetrafluoroethylene tube required to achieve the most adequate PA blood flow restriction. Also, combining this "tube-interposition-band-technique" with an expandable graft technology (such as exGraft tubes from PECA Labs, Pittsburgh, Pa) and 
preoperative computational modeling-based surgical planning could offer a very versatile and personalized way to optimize a PA band in the current era.

\section{Reference}

1. Salve G, Cole A, Nicholson I, Winlaw DS, Chard RB, Orr Y. Modified pulmonary artery banding: a novel strategy for balancing pulmonary blood flow with transposed great arteries. J Thorac Cardiovasc Surg Tech. 2021;9:111-20. 